\title{
ist \\ Animalidade transcendental: o problema da naturalização do a priori em Konrad Lorenz
}

Lorenzo BARAVALLE

\begin{abstract}
电
RESUMO

Um dos aspectos característicos da fundamentação epistemológica da etologia de Konrad Lorenz é a tentativa de síntese entre a teoria darwiniana e a gnosiologia kantiana. A partir dessa premissa, delinearemos, antes de tudo, uma breve história da tradição transcendentalista, focalizando a atenção em alguns elementos que seus críticos consideraram insustentáveis. Em segundo lugar, analisaremos a tentativa de Lorenz de implantar a estrutura transcendental em suas pesquisas etológicas, com uma consequente naturalização do conceito de "a priori". Em terceiro lugar, veremos como a atribuição de a priori próprios das espécies particulares abre a possibilidade de interpretar a epistemologia de Lorenz de duas maneiras distintas, aparentemente conflitantes. Finalmente, preferiremos uma dessas interpretações e mostraremos como ela permite o entendimento das distintas modalidades de conhecimento animal e humano.
\end{abstract}

Palavras-chave $\bullet$ Animais. Humanos. A priori. Epistemologia evolucionista. Naturalismo. Transcendentalismo. Darwinismo.

\section{INTRODUÇÃO}

Konrad Lorenz é conhecido, além de sua fundamental contribuição para a constituição da etologia como disciplina, também por sua original proposta epistemológica que combina evolucionismo, realismo e transcendentalismo em um quadro naturalista. Neste artigo, limitarei minha pesquisa, na medida do possível, à analise da função do kantismo e da filosofia transcendental em geral na economia dessa proposta. Essa escolha não é um fim em si mesma. Como veremos, o elemento kantiano tem a dupla função, no pensamento de Lorenz, de assegurar a descendência filogenética comum do ser humano e dos outros animais e, ao mesmo tempo, de garantir um acesso privilegiado para a compreensão das modalidades de conhecimento desses últimos. 
Enquadrando-o talvez um pouco artificiosamente, é possível insertar o pensamento de Lorenz no processo de naturalização da epistemologia oficializado por Quine (1969). Percebe-se, no trabalho de Lorenz, a pretensão de dissolver a teoria do conhecimento na pesquisa científica. Ele, embora madure suas ideias filosóficas no contato com os neokantianos de Königsberg, opõe-se a eles com respeito à ideia de que a filosofia transcendental seja a garantia última do conhecimento científico experimental. Para o biólogo, a objetividade é dada pelos resultados concretos empíricos das pesquisas, e isso representa um dado primitivo e irrenunciável, que nenhuma filosofia primeira, com suas noções abstratas e apartadas da experiência, pode arrebatar. Contudo, diferentemente de Quine e de outros defensores de epistemologias naturalistas, Lorenz não visa acabar com o legado de Kant. A naturalização da epistemologia não é uma renúncia à reflexão filosófica, mas um empreendimento que se manifesta como uma troca contínua entre especulação e ciência. Conforme esse ideal, as noções de "sintético a priori", "esquema”, "coisa-em-si” são deslocadas por Lorenz, junto com outras, passando a constituir elementos internos à pesquisa sobre o comportamento animal, sendo, assim, reinterpretadas à luz do darwinismo.

Para compreendermos melhor o programa lorenziano de modo a poder avaliar sua contribuição, começarei apresentando algumas ideias fundamentais sobre o desenvolvimento do kantismo, desde suas origens até a crise de seus fundamentos. Isso nos colocará na posição de poder discutir o conteúdo dos textos mais filosóficos do vienense fundador da etologia, a saber, o artigo de 1941, "La teoria kantiana de lo apriorístico bajo el punto de vista de la biologia actual" (1984, [1941]); o "manuscrito de Rússia", elaborado entre 1944 e 1948 durante o aprisionamento em um campo soviético, e publicado postumamente com o título $A$ ciência natural do homem (1993); e, finalmente, $A$ outra cara do espelho (1974), que constitui, de alguma maneira, uma síntese dos trabalhos anteriores e é, talvez, o escrito mais completo dos três. ${ }^{1} \mathrm{Na}$ conclusão, discutiremos a viabilidade da proposta de Lorenz, tentando corrigi-la onde houver necessidade, com a finalidade de apresentar um quadro coerente da relação entre conhecimento animal e humano.

1 Na verdade, vale a pena lembrar que nem este último nem o "manuscrito de Rússia" são obras acabadas. Lorenz (1974) devia ser composto por duas partes, mas a segunda nunca veio à luz. Da mesma maneira, Lorenz (1993) termina depois da primeira parte, embora inicialmente estivessem previstas quatro. Para mais detalhes sobre a questão, ver Margalef (1993) e Cranach (1993). 
Animalidade transgendental: o problema da naturalização...

\section{BREVE HistóRIA DO APOGEU E DO DEGLÍNIO DO TRANSGENDENTALISMO KANTIANO}

Seguindo uma linha interpretativa geralmente aceita (cf. Bird, 1962; Allison, 1983; Maddy, 2000), podemos considerar a primeira crítica kantiana como uma tentativa de mediar duas tendências epistemológicas aparentemente extremas e inaceitáveis: por um lado, o idealismo empírico de Berkeley e, por outro, o realismo transcendental de Locke. Conforme essa linha interpretativa, a questão que dividia Locke e Berkeley era a possibilidade de representar uma imagem verdadeira e unitária da "realidade", em contraste com a "aparência", isto é, a totalidade das impressões sensíveis multíplices e indiscriminadas. Locke colocara os termos do problema, distinguindo as qualidades primárias, tais como extensão, figura, número etc., possuídas objetivamente pelas coisas, das secundárias, tais como as cores, que acabariam por ser meros acidentes da ação das coisas sobre nosso aparato sensível e, portanto, irremediavelmente subjetivas. Dadas essas coordenadas, o conhecimento verdadeiro - empírico - consistiria, segundo Locke, em estabelecer correlações entre as qualidades primárias, recusando as "interferências" causadas pelas qualidades secundárias. Todavia, a factibilidade desse programa era dificultada pelo fato de não existir um critério, ele mesmo empírico, para distinguir os dois tipos de qualidades. A solução de Locke para esse problema era, então, a de admitir que tal critério não é dado pela experiência em si, mas pela atividade associativa do intelecto o qual, correlacionando as ideias, captura a necessidade das relações entre as qualidades primárias.

É evidente que a mente não conhece as coisas imediatamente, mas somente por meio da intervenção das ideias que tem delas. Nosso conhecimento, portanto, é real apenas na medida em que há uma conformidade entre nossas ideias e a realidade das coisas (Locke, 1959 [1690], rv. lv. 3).

Com esse tipo de explicação, Locke acabava afirmando mais do que um empirista deveria poder razoavelmente sustentar. A conexão (conformidade) entre o intelecto e as coisas como elas são implica que as coisas são de alguma maneira: elas são reais, em um sentido que não pode ser simplesmente apreendido mediante nossa sensibilidade e que, portanto, deveria ficar fora de uma filosofia natural. Com razão, o bispo Berkeley (1965 [1710]), considerando insustentável essa intromissão do intelecto na justificação do conhecimento, preferiu rejeitar a distinção entre qualidades primárias e secundárias e, com ela, a distinção entre a realidade e as aparências. Segundo Berkeley, a realidade há de ser identificada com a experiência sensível. Carece de sentido pergun- 
tar se esta última é mais ou menos conforme às "coisas", cuja realidade independente não é justificada a partir da experiência.

Para eludir essa situação aparentemente paradoxal, Kant (1986 [1781/1787]) distingue entre dois níveis epistemológicos, o empírico e o transcendental, e, poderíamos dizer, reconhece às noções de "realidade" e "aparência" uma implícita polissemia, dependente do nível no qual os conceitos são empregados. No primeiro nível, Kant defende um realismo empírico, isto é, rejeita a identificação de qualidades primárias e secundárias característica do que ele define como idealismo empírico proposto por Berkeley. Para Kant, como para Locke, devemos diferenciar entre características objetivas (a realidade) e subjetivas (as aparências) da experiência. É bem conhecida, a esse propósito, a passagem na qual Kant distingue a aparência do arco-íris da realidade do fenômeno de refração que sofre a luz do Sol pelas gotas de chuva (1986 [1781/1787], A46/ B63). O fenômeno da refração, que se apresenta ao sujeito como objetivo, e a aparência empírica do arco-íris, que é meramente subjetiva e ilusória, não podem ter o mesmo estatuto epistemológico. E todavia, de acordo com Berkeley, a exatidão de nosso juízo sobre o fenômeno da refração não pode ser garantida por uma suposta conformidade com as "coisas", como sustentava Locke.

A solução de Kant, como é sabido, é que a cognoscibilidade do fenômeno é dada pelo fato de que este se apresenta sempre a nossa experiência dentro das formas puras da sensibilidade, o espaço (euclidiano) e o tempo (sequencial). Estas são anteriores à experiência, são a priori, necessárias e universais. Assim como a sensibilidade, também nosso intelecto é caracterizado por formas a priori, a saber as categorias (doze, repartidas em quatro classes: quantidade, qualidade, relação e modalidade). O conhecimento é determinado pela subsunção do dado sensível às categorias mediante um juízo sintético. Os juízos determinantes (como o que estabelece as características físicas do arco-íris) adquirem objetividade - em contraposição aos juízos meramente reflexivos, subjetivos - só se as categorias do intelecto são apropriadamente conectadas com as impressões sensíveis mediante os esquemas transcendentais, representações (também a priori) que asseguram a legitimidade da interação entre a faculdade da intuição sensível e a faculdade do intelecto. ${ }^{2}$ Colocando de novo a questão, podemos agora dizer que, para Kant, existe a possibilidade do conhecimento objetivo (em oposição a Berkeley) e, todavia, esse conhecimento não é dado pelas características intrínsecas do objeto (diferentemente de Locke), mas pela "configuração" gnosiológica do sujeito e a conformidade de seus juízos com a experiência fenomênica.

2 Obviamente, trata-se de uma exposição da arquitetura kantiana do conhecimento extremamente resumida e, espero, não demasiado enganosa. A estrutura do texto não permite entrar mais nos detalhes mas, para uma exposição crítica acurada, podem ser consultados, por exemplo, Cassirer, 1948 [1918], Allison, 1983, Marcucci, 1997. 
Animalidade transgendental: o problema da naturalização...

Anteriormente, dissemos que no pensamento de Kant é possível falar de uma espécie de polissemia implícita nas noções de "aparência" e "realidade". E, de fato, no nível transcendental, o conceito de fenômeno - que, no nível empírico e para nós, seres sensíveis, representa a única realidade objetiva - é transposto e passa a ser associado ao conceito de aparência, em contraposição à noção de númeno ou coisa-em-si, isto é, de uma realidade além do mero fenômeno. Kant se considera um idealista transcendental, já que interpreta essa realidade além da experiência, a substância última do mundo, como mero limite negativo e inconcebível. As coisas-em-si ficam fora da ação de nossa sensibilidade, embora nosso intelecto, às vezes, sofra a tentação enganosa de aplicar-lhes suas categorias, atribuindo-lhes injustificadamente propriedades arbitrárias. Isso é o que faz também Locke quando confere realidade espaçotemporal às coisas (e não apenas aos fenômenos, como seria lícito), sem questionar a divergência entre o mundo fenomênico (para nós, seres sensíveis) e o mundo numênico. Ele é considerado um realista transcendental, porque, embora demonstre que o conhecimento parte de uma base empírica, chega a inferir dogmaticamente conclusões ontológicas que não são autorizadas pelo "tribunal da experiência” e, em geral, pela investigação epistemológica.

A caracterização puramente "negativa” da coisa-em-si pode gerar alguma perplexidade. Qual é a relação entre o fenômeno e o númeno? Não pode ser causal, já que a causalidade é uma categoria (pertencente à classe da relação) que, como tal, pode ser aplicada apenas a relações entre fenômenos, e o númeno, por definição, não é um objeto da experiência. Kant parece optar por uma interpretação genérica pela qual a coisa-em-si é um $x$, um marcador de posição que atrai nossos sentidos, mas nunca pode ser compreendido em sua dimensão ontológica, pois sua relação com o fenômeno é alógica. Essa solução, como veremos, não satisfará Lorenz.

Deixando, por ora, de lado essa questão - que foi, contudo, decisiva para a recaída do idealismo transcendental no idealismo absoluto de Fichte-, vamos considerar outro problema do sistema kantiano, que possibilitou, nas primeiras décadas do século xx, o giro linguístico e semântico dos empiristas lógicos e, finalmente, a naturalização da epistemologia kantiana. O sucesso das geometrias não euclidianas e da teoria da relatividade, ao longo dos séculos xIX e xx, induziu vários filósofos e cientistas a colocar em dúvida o status de necessidade epistemológica que Kant atribuía ao espaço e ao tempo, enquanto formas puras da sensibilidade. O sistema kantiano justifica a priori a geometria euclidiana e a concepção linear do tempo com base nos nossos sentidos. Por sua vez, estes a priori são a única garantia da aplicação correta e objetiva do intelecto a priori e das categorias, o que confere legitimidade universal aos juízos e, consequentemente, à física newtoniana. Uma vez que a universalidade da geometria euclidiana e da ordem temporal são postas em discussão, o esquematismo transcendental perde o 
fundamento sobre o qual as categorias do intelecto pretendem ser aplicadas a priori com caráter necessário. Se outras concepções do espaço e do tempo são possíveis, por que deveríamos limitar nosso conhecimento ao que nos mostram os sentidos? Por outro lado, se os sentidos já não são a única fonte confiável para a aplicação dos esquemas - e, portanto, das categorias - como o kantiano justificará o conhecimento objetivo? Como poderá distingui-lo das fantasias metafísicas que, ao desconectar o intelecto da sensibilidade, aparecem tão facilmente na nossa imaginação?

Carnap (1967 [1928]; 1950) foi dos primeiros filósofos a tomar seriamente o desafio constituído pela aparente inadequação do sistema apriorístico kantiano com relação aos desenvolvimentos da ciência contemporânea (cf. Coffa, 1991, p. 259-71). Com a distinção entre questões internas e externas a uma linguagem teórica Carnap (1950) pretende reproduzir - e, poderíamos dizer, "secularizar" - a distinção kantiana empírico/transcendental em uma perspectiva convencionalista (cf. Maddy, 2000). Essa distinção tem a função de delimitar o âmbito da investigação científica (isto é, a questão interna) a um determinado sistema de referência linguístico que impeça a formulação de questões metafísicas (externas), como aquelas concernentes ao realismo e ao idealismo (que tanto tinham interessado o debate anterior). As características do sistema de referência são definidas a priori, por meio de regras sintáticas e semânticas, relativamente convencionais, que estabelecem inferências válidas e critérios de testabilidade. Essas regras não possuem conteúdo empírico e, contudo, assim como os a priori kantianos, prescrevem limites ao que pode ser razoavelmente conhecido por via empírica, excluindo do conhecimento objetivo o que não pode ser dito na linguagem da ciência.

A caracterização da questão externa feita por Carnap é preeminentemente negativa, assim como a caracterização de Kant da coisa-em-si. Os enunciados ontológicos tradicionais são pseudoenunciados que devem ficar fora do discurso da ciência, já que não temos maneira de testá-los. Em aberta polêmica com esse tipo de dicotomias, Quine (1963) sustentará que elas não representam fielmente o desenvolvimento real das disciplinas científicas: questões científicas (internas) e questões ontológicas (externas) misturam-se constantemente, e nunca é dado um parâmetro definitivo de confirmação ou de falsificação. Qualquer separação é arbitrária e impede o livre desenvolvimento da pesquisa científica, a qual muitas vezes mostra como questões precedentemente consideradas metafísicas são, na verdade, empíricas. 
Animalidade transgendental: o problema da naturalização...

\section{A naturalização lorenziana}

Para melhor entender a posição de Lorenz é preciso, em primeiro lugar, diferenciar seu trabalho do projeto de naturalização proposto por Quine e desenvolvido por muitos evolucionistas. Para fazer isso, é útil colocar as duas propostas dentro das categorias interpretativas kantianas que empregamos precedentemente, a saber, idealismo e realismo, empírico e transcendental.

Como já antecipei na introdução, tanto para Lorenz como para Quine, a resposta às perguntas da epistemologia tradicional deve ser procurada nas ciências empíricas. Para os dois autores, isso implica, ainda que em graus diferentes, reconduzir a problemática transcendental (ou externa) a um único domínio (e um único método) de investigação. Em Quine, esse projeto é muito mais extremo e assume o aspecto de uma verdadeira redução interdisciplinar. Para ele, não faz sentido conservar as relíquias da velha epistemologia, como o conceito de a priori. De fato, sua crítica a Carnap visa precisamente eliminar do âmbito da nova epistemologia essa limitação artificial ao domínio da ciência. Independentemente de importantes matizes (que, contudo, não cabe discutir aqui), podemos dizer que o projeto quineano é realizado no plano de um realismo empírico privado de qualquer correlação com uma questão transcendental distinta, a qual, ao contrário, é "dissolvida" na pesquisa científica. Os cientistas que realizarão esse ideal explicativo na área da biologia evolutiva, na área da sociobiologia e, sucessivamente, da psicologia evolucionista (que Lorenz (1974), ante litteram, uniria sob o rótulo de "behavioristas") reconhecerão em Hume o primeiro inspirador desse tipo de análise (cf. Lumsden \& Wilson, 1981; Ruse, 1986). A ciência, nessa perspectiva reducionista, é o último passo evolutivo (até agora) de uma luta pela sobrevivência na qual ser "bons animais indutivos" representou, casualmente, um traço adaptativo fundamental (cf. Giere, 1985). O evolucionista deve compreender os fundamentos de sua investigação a partir dos dados de sua investigação, e isso não implica nenhum círculo vicioso, já que se trata de um trabalho de contínua interação entre a descoberta dos fundamentos racionais e a aplicação dessas descobertas na metodologia. O problema kantiano (e humeano) da objetividade do conhecimento é resolvido mediante o suporte científico fornecido pela teoria da seleção natural, a qual, segundo a proposta de Quine, confere garantia, sempre revogável, da adequação de nossas intuições sobre a natureza.

Embora aceite a importância da indução no desenvolvimento tanto natural como científico (cf. Lorenz, 1993, p. 74-86), ${ }^{3}$ Lorenz segue um caminho parcialmente dife-

3 Eis aqui uma grande diferença entre a concepção evolucionista de Lorenz e a de Popper, muitas vezes passada por alto (cf. Ruse, 1986; Munz, 1993; Martinez \& Olivé, 1998). 
rente da maioria dos naturalistas. Ele se declara, de partida, realista em um sentido bem distinto do que se poderia razoavelmente atribuir a Quine. Citando Monod, Lorenz abre seu livro de 1974, escrevendo que "a pedra angular do método científico é o postulado da objetividade da natureza” (p. 17) e esclarece, nas páginas seguintes, que a afirmação tem um duplo sentido. Por um lado, o cientista deve supor a realidade do mundo exterior como um fato primitivo. Por outro, ele deve também aceitar que o sujeito, enquanto sujeito do conhecimento, forma parte da natureza e estabelece relações (causais) com a realidade, as quais são elas mesmas reais e, portanto, não podem ser ignoradas pela investigação científica. ${ }^{4}$ Lorenz reconhece que essa noção tão extensa de realidade poderia levá-lo ao extremo oposto do realismo, a uma espécie de idealismo empírico (por ele representado pela posição de Goethe), no qual o plano fenomenológico da aparência subjetiva mistura-se inextricavelmente com as qualidades primárias. Porém, Lorenz opõe-se explicitamente a essa posição (1993, p. 66; 1974, 25-9). Segundo ele, qualquer filosofia idealista falha por completo na compreensão da realidade. $\mathrm{O}$ conhecimento não consiste em levar o mundo para o sujeito, mas o sujeito para o mundo. O conhecimento é uma constante objetivação das coisas no plano fenomênico, em um processo sem fim, no qual se revelam as próprias estruturas do conhecimento.

Essa última frase, aparentemente tão densa e um pouco obscura, resume, na verdade, bastante bem os principais elementos do projeto epistemológico lorenziano. Podemos distinguir nele três componentes: primeiro, a confiança na possibilidade de passar, por meio da pesquisa empírica, do plano fenomênico e aparentemente subjetivo à objetividade científica; segundo, a admissão de que essa pesquisa não chegará nunca a seu fim (mas não por isso deve ser abandonada); terceiro, a definição da finalidade da ciência (e, mais exatamente, das ciências da vida) como a compreensão das condições de possibilidade da própria compreensão.

O primeiro componente faz de Lorenz uma espécie de realista transcendental, embora, como veremos em breve, esse rótulo não seja totalmente adequado. $\mathrm{O}$ trabalho do cientista é a compreensão do mundo através de como ele é. Não há espaço para um númeno na ciência, uma coisa-em-si ininteligível e inalcançável, mas apenas para graus de incerteza. Talvez a realidade não se mostre nunca por completo, mas pode ser investigada cientificamente sem receios metafísicos (cf. Lorenz, 1984, p. 96 ss.). Se as coisas nos aparecem de certa maneira, não pode ser uma mera coincidência, pois é absurda a ideia de que a relação entre a coisa-em-si e o fenômeno seja a-lógica

4. Lorenz (1974, p. 21) cita também Bridgman: "Não é lícito separar o objeto do conhecimento e o instrumento do conhecimento, eles devem ser considerados como um único conjunto". O trecho refere-se a um comentário do autor sobre a interpretação da mecânica quântica de Bohr e revela como Lorenz - sempre atento ao papel ativo do sujeito no conhecimento - também é influenciado pela física de seu tempo e, em particular, pelo princípio de incerteza de Heisenberg. 
Animalidade transgendental: o problema da naturalização...

(cf. Lorenz, 1984 [1941], p.105-7). Nossa conexão biológica com o mundo, que emerge com toda sua força na teoria evolutiva de Darwin, é uma evidência positiva a favor da correspondência - ou, até, da relação causal - entre o mundo "numênico" e nossa sensibilidade fenomênica. Como explicar, de outra maneira, nosso sucesso adaptativo na interação com a realidade?

Nossas formas de sensibilidade e nossas categorias, anteriores a toda experiência individual, ajustam-se ao mundo exterior exatamente pelas mesmas razões pelas quais se ajusta o casco do cavalo, já antes de seu nascimento, ao terreno da estepe, e as nadadeiras do peixe, já antes de sair do ovo, à agua (Lorenz, 1984. [1941], p. 93).

As adaptações, tanto morfológicas como cognitivas, refletem a realidade como um espelho (1994, p. 58-9), talvez com alguma imperfeição, mas fielmente.

O segundo componente matiza a primeira tese, que poderia ser objeto de críticas parecidas às dirigidas contra o realismo transcendental "ingênuo" de Locke, já que a confiança na coincidência entre a realidade e nosso mundo fenomênico poderia parecer pouco "naturalista” e muito "metafísica”. Lorenz considera que, embora a conexão com a realidade seja indubitável, nunca chegaremos a uma teoria completa sobre ela, porque ela nunca se revelará por completo a nossos sentidos. Nossas teorias serão sempre limitadas a elementos particulares do mundo que, ainda que certeiros, não constituirão nunca a totalidade do cognoscível:

Sempre haverá na prática ao menos um fato real do universo que estará além da possibilidade de um conhecimento seguro, até para os seres racionais mais superiores que possamos conceber. Esse fato seria constituído, precisamente, por esses seres racionais mesmos (Lorenz, 1993, p. 67).

O ser humano é irremediavelmente limitado em sua ação cognoscitiva por causa de sua particular estrutura, mas isso, longe de ser uma debilidade, é também uma força. De acordo com o ideal metodológico popperiano (Popper, 1962), Lorenz vê na contínua sucessão de conjecturas e refutações um dos traços característicos do que ele batiza como realismo hipotético (Lorenz, 1974, p. 29 ss.). Qualquer passo para frente, na evolução filogenética das estruturas cognitivas animais assim como de nossas teorias, constitui um acréscimo objetivo do conhecimento, embora qualquer hipótese sobre a realidade no seu conjunto seja sempre meramente parcial.

O último componente do projeto epistemológico lorenziano reforça essa intuição e esclarece suas finalidades teóricas. A tarefa última da epistemologia naturalizada 
- que, para Lorenz, tem como máxima expressão a epistemologia evolucionista de Donald Campbell (cf. 1974a, 1974b) - é a explicação dos mecanismos que estão na base de nossa cognição, a saber, dos a priori do conhecimento fenomênico. Partindo de um pressuposto fortemente adaptacionista, Lorenz afirma então que a maneira mais cientificamente promissora para chegar a esse objetivo é analisar como a evolução chegou a formar

os mecanismos que, imunizados contra qualquer mutação, permitem-nos, com base nas mensagens sensoriais presentes, dar “juízos” imediatos acerca do mundo circunstante, e constituem a base de qualquer experiência (1974, p. 58).

Dado que "o caminho que conduz à compreensão do homem passa pela compreensão animal, da mesma maneira que o caminho que conduz à aparição daquele passou, sem dúvida nenhuma, por este" (Lorenz, 1993, p. 23), é a investigação etológica a única que, para Lorenz, permite levar a cabo (ainda que sempre de forma incompleta) esse projeto. O objetivo da pesquisa assim apresentada é descrever a evolução do a priori, analisando como se formam sistemas perceptivos e cognitivos cada vez mais estáveis e refinados nas várias espécies, por meio dos processos seletivos.

Antes de considerar nos detalhes a realização do projeto lorenziano, vamos esclarecer mais algumas diferenças entre seu projeto e os que esbocei anteriormente, de inspiração quineana. Como Lorenz, também os sociobiologistas e os psicólogos evolutivos acreditam que a teoria da seleção natural represente um fundamento sólido para justificar nossas afirmações sobre como funcionam e como se desenvolveram os sistemas cognitivos animais e humano. Contudo, os psicólogos não consideram que o aspecto fenomênico e subjetivo do ato cognoscitivo represente um genuíno problema para a investigação científica. Como já dissemos, sociobiologia e psicologia evolutiva são teorias reducionistas, no sentido que sustentam que a compreensão das condições físicas (em um sentido amplo) subjacentes a um determinado comportamento, ou módulo cognitivo, fornece uma explicação relativamente completa e satisfatória da aparição e do funcionamento desses comportamentos. O sujeito do conhecimento é passivo, limita-se a ser objeto das forças seletivas, as quais determinam o sucesso de suas faculdades psicológicas em termos, direta ou indiretamente, reprodutivos. Para Lorenz, na base da vida, já existe uma "experiência” fenomênica de representação da realidade, um mecanismo teleológico que constitui um elemento causal que não pode ser negligenciado. A adaptação é, por si mesma, uma aquisição de conhecimento que não é simples armazenamento passivo, mas contínua troca de energia e informação com o ambiente, em um constante processo de retroalimentação (cf. 1974, p. 56-62). 
Apresentando essas ideias, ao longo de suas obras, Lorenz admite sua dívida com a psicologia da Gestalt, a cibernética, a teoria dos sistemas (principalmente na figura de von Bertalanffy) e o emergentismo (mais exatamente, a teoria dos "estratos" de Nicolai Hartmann). Em particular, essa última influência deve ser um pouco matizada. Lorenz aceita a ideia de uma evolução emergente de propriedades ontologicamente "novas" como um princípio básico e irrenunciável. Essa postulação deve ser entendida como o reconhecimento da impossibilidade de fornecer uma reconstrução mecanicista da gênese da complexidade no mundo vivente. Cada nível de organização (inorgânico, orgânico, psíquico e espiritual) emerge em um determinado momento histórico, a partir do qual se torna possível um novo equilíbrio homeostático. E, embora os níveis mais complexos nasçam a partir da integração de funções mais simples (e mantenham-se também graças a elas), é desarrazoado - diz Lorenz frente a certa biologia e a certa psicologia behaviorista - tentar explicar propriedades dos níveis mais complexos a partir da simples "soma" de funções presentes nas formas orgânicas mais simples: o evolucionismo reducionista é absurdo (cf. Lorenz 1974, p. 74-85). A complexidade ontológica não deveria, contudo, levar-nos a desesperar de conhecer o funcionamento da evolução das formas de vida. Ao contrário, é precisamente com a aceitação de que existem vários níveis de propriedades emergentes que podemos começar nossa investigação. É apenas adotando uma posição holista (Lorenz, 1993, p. 197-210), que considere as partes como indissociáveis do todo, que podemos esperar alcançar a verdadeira compreensão das dinâmicas evolutivas e, com elas, do comportamento animal e humano.

\section{A eVolução do a priori}

Lorenz caracteriza sua perspectiva sobre a evolução da cognição nos seguintes termos: os esquemas de compreensão da realidade são ontogeneticamente a priori, mas filogeneticamente a posteriori (cf., por exemplo, Lorenz, 1984 [1941], p. 90; 1993, p. 65). Com isso ele quer dizer que, embora existam mecanismos cognitivos inatos em cada indivíduo - que dirigem teleologicamente sua ação e estabelecem, assim, suas chances adaptativas -, o processo pelo qual esses mecanismos fixaram-se na espécie não depende de nenhum projeto anterior, mas é o resultado de uma variação cega e de retenções seletivas, conforme o modelo darwinista tradicional. ${ }^{5}$ Nas reconstruções filoge-

5 Seria preciso considerar se esse modelo é realmente compatível com o modelo emergentista de Hartmann, como Lorenz acredita. A questão é complexa e não pode ser discutida aqui (fornecerei, entretanto, razões para dar uma resposta negativa à questão, no final deste item), mas vale a pena lembrar que uma das maiores qualidades epistemológicas do darwinismo tradicional é que ele não precisa recorrer a outro mecanismo além da seleção natu- 
néticas, o a priori joga, podemos dizer, o papel de elemento retentivo da evolução (cf. 1984 [1941], p. 100). "O 'a priori', que determina as formas nas quais se manifestam as coisas reais de nosso mundo, é, dito brevemente, um órgão, e de maneira mais exata, a função de um órgão" (Lorenz, 1974, p. 92). O estabelecimento de um a priori coincide com a seleção e a manutenção de um traço morfológico, cognitivo ou comportamental, enquanto as contingências históricas e ambientais representam o elemento variável do processo evolutivo.

Dados esses pressupostos, Lorenz (1974) procede à descrição do que considera ser os estágios mais importantes na evolução da cognição. ${ }^{6}$ Já nas primeiras fases da evolução (isto é, a partir da emergência - que Lorenz chama de fulguratio - do orgânico), apareceram mecanismos fixos de aprendizagem que viabilizaram movimentos e interações com o ambiente de acordo com os estímulos recebidos. Eis assim, por exemplo, a reação ameboide, a cineses, a reação fóbica e, em um nível levemente superior, os movimentos desencadeantes inatos, ${ }^{7}$ a coordenação hereditária e os movimentos instintivos. Trata-se de funções comportamentais que não permitem o armazenamento da informação, mas Lorenz considera que já neste nível o organismo transcende a mera interação mecânica com o mundo e mostra uma subjetividade própria:

[esses mecanismos] são assegurados contra qualquer possível modificação, e devem sê-lo, porque, anteriores a qualquer experiência, eles constituem o fundamento de qualquer possível experiência. Deste ponto de vista, eles correspondem perfeitamente à definição que Kant deu do a priori (1974, p. 117).

Nos estágios evolutivos posteriores, os organismos adquirem faculdades de aprendizagem que modificam o comportamento ao longo da vida. Trata-se da evolução de programas abertos (cf. Mayr, 1970), desenvolvidos na fase embrionária, que conferem ao organismo a capacidade de captar do ambiente as características fenomênicas que condicionam seu comportamento. Trata-se ainda de reações incondicionadas: a informação ambiental, se repetida, potencializa a reação sem que o organismo possa com-

ral para explicar a complexidade, enquanto o emergentismo nega justamente que as coisas sejam assim tão fáceis. Aderindo a este último, Lorenz parece desconfiar da completude do primeiro. Talvez isso não seja, em si, algo reprovável, mas é interessante notar que Popper, que sofre do mesmo ceticismo, acaba tendo problemas na hora de encontrar uma formulação coerente de seu programa evolucionista (cf. Vecchi \& Baravalle, no prelo).

6 Lorenz (1994, p. 36 ss., p. 226) apresenta um esquema menos detalhado dos principais mecanismos cognitivos e comportamentais, mas em grandes traços equivalente ao que analisamos aqui.

7 Lorenz (1994, p. 40) insiste na importância do conceito de esquema desencadeante inato, que é considerado como "herdeiro" naturalizado do esquematismo transcendental de Kant. Esse conceito denota a capacidade, comum ao homem e aos animais, de se representar um estímulo internamente e assim (re)agir em conformidade com ele, respondendo a padrões inatos de comportamento. 
portar-se de maneira distinta. ${ }^{\mathbf{8}}$ Lorenz caracteriza esse estágio pela aparição de uma sensibilidade mais desenvolvida e de uma capacidade indutiva primitiva, que permite um simples armazenamento repetitivo de informação sensível, associada cognitivamente a uma reação. Filogeneticamente, emerge mais tarde a capacidade de ter reações condicionadas, a qual implica um discernimento sobre que tipo de fenômeno deve ser considerado relevante para agir. Essa faculdade integra sensibilidade e ação animal em um sistema de retroalimentação complexa com respeito ao ambiente, e manifesta-se em algum tipo de estado consciente próprio de cada espécie. A partir desse estágio, desenvolvem-se habilidades motrizes mais complexas e, com elas, a representação fenomênica do espaço. Esta permite, por sua vez, a "objetivação" das formas, por meio de um processo gestáltico (1974, cap. 4-6). Durante esse processo, realiza-se a emergência de uma complexidade psíquica sobre a base orgânica. Esta, na verdade, permeia gradualmente a evolução biológica toda, de uma maneira dificilmente dissociável do substrato físico, ou seja, a vida é, para Lorenz, identidade psicofísica (cf. 1974, p. 284-6).

De acordo com a finalidade da etologia, uma das principais preocupações de Lorenz é, como vimos, a de descrever vários níveis de acesso ao "real", ao mundo, de acordo com o grau evolutivo da espécie. E, embora seja quase impossível conceber uma subjetividade diferente da humana, emergem da análise filogenética importantes informações sobre a experiência vivida pelo animal. 9 Pode-se supor, sugere Lorenz, que os organismos mais simples tenham um acesso ao mundo no qual a cisão entre o sujeito e o mundo ainda não é totalmente dada. Isso corresponderia a um grau de conhecimento relativamente baixo, mas não por isso ausente; qualquer sistema orgânico evolutivamente programado para dar resposta a um estímulo comporta retroalimentação, e esta parece ser uma condição suficiente para que possamos considerar uma estrutura como um a priori do conhecimento. É só relativamente tarde, no processo filogenético, que as "aparências" fenomênicas perceptivas separam-se e ao mesmo tempo permitem a individuação de uma realidade objetal distinta do sujeito. Constitui-se, assim, o que estamos acostumados a chamar de "consciência”. Segundo Lorenz, são necessárias para isso faculdades pré-conceituais raciomorfas (cf. Brunswik, 1957). São elas em ordem de aparição:

8 É o caso, para citar um exemplo amplamente estudado por Lorenz, do fenômeno do imprinting em numerosas espécies de aves.

9 Com certeza, Lorenz tinha um dom especial para essa tarefa. Sobre isso, Gregory Bateson escreve: "a empatia de Lorenz com os animais confere-lhe uma vantagem quase desleal sobre os outros zoólogos. Ele tem a capacidade de ler muitas coisas, e com certeza faz isso em uma confrontação (consciente ou inconsciente) entre o que vê o animal fazer e o que se sente em fazer a mesma coisa" (Bateson, 1979, p. 190-1). 
- a capacidade de elaborar representações espaciais complexas, intimamente relacionadas com as capacidades de movimento ocular e de deambulação;

- o armazenamento mnemônico através da aprendizagem seletiva e o consequente incremento de habilidades motrizes especializadas (dinâmicas reprodutivas particulares, diferenciação de atitudes de caça e de defesa);

- a curiosidade e a autoexploração (e, portanto, a consciência de si, por meio da observação de elementos do próprio corpo presentes no campo visual - apreciável já em muitos primatas, devido às capacidades motrizes oculares e corpóreas complexas);

- a imitação (por exemplo, o canto dos pássaros);

- a transmissão do conhecimento apreendido (como a migração das aves). ${ }^{10}$

O ser humano é o único animal no qual todas essas faculdades se dão conjuntamente (cf. 1974, p. 273). Mas elas, ainda que necessárias, não são suficientes para caracterizar o humano como tal. Sua aparição na cena evolutiva corresponde à evolução de um novo a priori (cf. 1974, p. 287), que Lorenz chama, em algumas ocasiões (cf. 1974, p. 29), de "aparato imagem do mundo". O processo filogenético anterior tem conferido aos organismos faculdades cada vez mais refinadas de interação com o ambiente. Não há, contudo, uma total independência das condições pré-determinadas pelo genoma nos seres que precederam evolutivamente a aparição do ser humano. Nossa relativa autonomia com respeito às bases genéticas torna-se possível só graças à emergência de uma novo grau de complexidade ontológica: a espiritualidade. Esta novidade emergente é, em certa medida, identificada com a faculdade da conceituação; e Lorenz considera que ela representa um acontecimento histórico ainda mais importante que a emergência do orgânico a partir do inorgânico (cf. 1974, p. 285). Os traços que caracterizam o salto ontológico são, sumariamente, a transmissão hereditária dos caracteres adquiridos e a expansão da vida intelectual no plano comunitário, a qual permite a construção social do que pode ser considerado "real". Ambas realizam-se no desenvolvimento das culturas particulares, as quais podem ser elas mesmas consideradas como sistemas viventes. Em outras palavras, a capacidade de conceituação fornece ao ser humano a possibilidade de colocar-se "fora de si", de iniciar uma nova evolução feita de tradições, novas formas de organização e teorias (cf. Munz, 1993, cap. 4).

Em minha opinião, devido talvez à excessiva confiança na metafísica de Hartmann, Lorenz parece levar a analogia entre evolução natural e evolução cultural demasiadamente a sério. A história é comparada por ele a um processo filogenético de sele-

10 Lorenz não é sempre explícito na hora de definir o que para ele corresponde a um a priori da experiência - em sentido próprio, ou seja, como esquema de conhecimento anterior a qualquer experiência - para distingui-lo das variedades de comportamentos associados a ele. Porém, isso não é de grande importância neste contexto. 
ção natural que expressa princípios transcendentais e imutáveis, que lembram as "leis históricas" de Toynbee (Lorenz, 1974, p. 296-7). Pode-se ler que "a subdivisão do mundo fenomênico em pares de opostos responde a um princípio ordenador inato em nós, a uma coação a priori do pensamento que pertence a seus primórdios" (1974, p. 298). Coerentemente com essa perspectiva, os últimos capítulos de Lorenz (cf. 1974) são dedicados a construir analogias com o método da análise filogenética e de outras disciplinas humanas, como a linguística e a antropologia. O suporte teórico dado por essas analogias parece ter, para Lorenz, o caráter conclusivo de que as esferas da vida "espiritual" devem ser governadas pelos mesmos mecanismos que caracterizam a evolução das formas orgânicas, apenas com um grau maior de complexidade, dado pela sobreposição de vários níveis de emergência causalmente relacionados.

Nesse ponto, mais do que em outras partes da obra, o autor segue Campbell (cf. 1974a, 1974,b) e Popper (cf. 1972) nessa empresa, a meu ver destinada ao fracasso, de estabelecer o ensaio e erro como mecanismo de qualquer processo histórico. A analogia sobre a qual se funda esse tipo de epistemologia evolucionista encontra-se fatalmente enfraquecida quando examinamos mais detalhadamente os vários processos históricos que pretende explicar. Estes últimos, embora tenham algo de seletivo no sentido darwiniano, não podem sem mais ser equiparados aos processos biológicos (cf. Ruse, 1986, p. 83-91; Thagard, 1998 [1980]). A mera transposição do aparato explicativo do darwinismo, ao invés de esclarecer a complexidade das dinâmicas culturais, põe em manifesto um sem fim de exceções, mostrando como a teoria é amplamente subdeterminada. Porém, a esse respeito, Lorenz encontra-se em uma posição ainda pior que a de Campbell e Popper, por outra razão. O apelo ao transcendentalismo parece, na análise da evolução cultural, forçoso. O problema é que a teoria da seleção natural termina sendo, para Lorenz, uma espécie de a priori do conhecimento histórico assim como a mecânica newtoniana era o a priori do conhecimento empírico para Kant. Porém, uma coisa é sustentar que o modelo darwiniano é útil no estudo das dinâmicas culturais, mas falível assim como qualquer outro esquema conceitual; outra coisa bem diferente é afirmar que ele é o modelo de investigação, a teoria unificadora aprioristicamente justificada com base biológica. A primeira opção é própria de um cientista, a segunda trai a ambição do metafísico. O recurso a Kant, por parte de Lorenz, é muitas vezes impróprio, já que é um pretexto para apoiar suas próprias teses, produzindo uma espécie de petitio principii transcendental. O fato de que a evolução, biológica e cultural, forneceu esquemas de interpretação da realidade, tal como a teoria darwiniana, não implica que essa teoria determine infalivelmente nossas intuições sobre qualquer processo histórico.

Esse não é o único ponto fraco da proposta de Lorenz. Embora ele rejeite uma perspectiva antropocêntrica - amiúde repete que cada estrutura cognitiva animal tem 
sua própria objetividade na representação da realidade (cf. 1984 [1941], p. 91-2; 1993, p. 71, 149) -, a imagem emergentista que propõe da evolução biológica é tendencialmente voltada ao progresso em direção ao ser humano (cf. 1984 [1941], p. 103; 1993, p. 68). É significativo, a esse propósito, que Lorenz (cf. 1974, cap. 7) insista muito mais sobre as diferenças entre o humano e o animal que sobre as semelhanças, focalizando a atenção sobre a imensa diferença de grau produzida, segundo ele, pela fulguratio espiritual. "Todo o homem não está no animal, mas todo o animal está no homem" (1993, p. 196) é um refrão acertado para descrever sua posição, ou seja, a compreensão animal e seus a priori específicos parecem estar filogeneticamente contidos, para Lorenz, no ser humano. Caponi (cf. 2012) mostra como essa tese não encontra nenhuma justificação no corpus teórico do darwinismo. A árvore da vida não é uma pirâmide. As capacidades cognitivas de cada espécie diferenciam-se a partir de sua própria separação filética, e não podem ser oferecidas comparações absolutas entre elas. "Nenhuma espécie está toda contida em seus ancestrais; cada espécie tem suas autopomorfias" (Caponi, 2012, p. 187), a saber, cada espécie tem suas peculiaridades irredutíveis às de outras espécies, determinadas por sua particular colocação na árvore da vida. ${ }^{10} \mathrm{Se}$, de acordo com as intuições de Lorenz, existem formas específicas de conhecimento animal, e cada espécie alcança certa objetividade fenomênica própria, deveríamos então admitir que não existe uma hierarquia absoluta dos "órgãos" do conhecimento a priori.

\section{Rumo a UMA EPISTEMOLOGIA EGOLÓGICA}

Critiquei, no final do item precedente, as tendências emergentistas e antropocêntricas na reconstrução filogenética de Lorenz. Elas são inegáveis, mas também vale a pena notar (como já fiz de passagem) que amiúde são acompanhadas por observações abertas a outras interpretações.
(...) esse limite, que separa o perceptível do transcendente, há de variar em cada espécie distinta de seres vivos. A localização desse limite, definidor da espécie, há de ser objeto de investigação caso a caso. Incluir na definição do existente em si a localização atual, puramente casual, que tem esse limite na espécie humana significaria para nós um antropomorfismo injustificável (Lorenz, 1984 [1941], p. 91).

\footnotetext{
11 Em cladística, define-se autopomorfia como uma característica própria de uma espécie, de aparição mais recente, em relação a uma plesiomorfia, uma característica mais antiga, da qual a espécie vai se distanciando.
} 
Animalidade transgendental: o Problema da naturalização...

Um pouco mais adiante, Lorenz acrescenta que

o que é verdadeiramente necessário às ciências naturais, com urgência, é um conceito de realidade absoluta, que deve ser o menos antropomórfico possível e deve ter a máxima independência com respeito à localização atual, casual, dos limites da capacidade perceptiva humana. A realidade absoluta não há de ser afetada de maneira alguma pelo fato de estar refletida ou não, e até que ponto, no cérebro atual de um ser humano ou de qualquer outra criatura de vida efêmera (p. 92).

Como definir, de maneira minimamente coerente, esse "conceito de realidade absoluta" a partir dos pressupostos naturalistas apresentados por Lorenz? Como alcançar, ainda que vagamente, uma representação de algo que deveria ter "máxima independência dos limites da capacidade perceptiva humana"? Em minha opinião, abrem-se dois caminhos alternativos, ambos, em maior ou menor medida, sugeridos por Lorenz. O primeiro é o da epistemologia evolucionista. Já vimos alguns de seus limites, pelo menos na formulação tradicional de Campbell (1974a, 1974b) e Popper (1972). Contudo, vale a pena voltar um pouco ao assunto. Chamarei a segunda opção de epistemologia ecológica, tentando, assim, caracterizar uma possível área de estudo para a comparação da cognição humana e animal.

Com respeito à primeira possibilidade teórica, Lorenz é bastante explícito (cf. 1974, cap. 1). Ela se funda na suposta ruptura que existe entre o ser humano e as outras formas orgânicas. Usando a terminologia de Munz (cf. 1993, p. 154 ss.), o animal é uma "teoria encarnada" sobre o ambiente, enquanto o ser humano é capaz de gerar teorias que são "organismos desencarnados", mais ou menos adaptados as nossas exigências de sobrevivência e conhecimento. Obviando a questão do que é o ser humano - a qual, no quadro do darwinismo, não se poderia subtrair às dificuldades levantadas por $\mathrm{Ca}-$ poni (cf. 2012) -, essa caracterização consegue diferenciar o tipo de atividade cognoscitiva que caracteriza cada domínio evolutivo, o animal e o humano, com base na capacidade deste último de elaborar hipóteses. $\mathrm{O}$ animal é mais limitado que o homem, por causa da incapacidade de revocar sua "teoria" sobre a realidade; enquanto o ser humano pode aproximar-se da objetividade epistêmica, da coisa-em-si, sem precisar se transformar biologicamente. O conceito de "realidade absoluta" procurado por Lorenz seria, nessa perspectiva, o conceito fornecido por uma teoria que supere nossa limitação biológica de alcançar uma representação cada vez mais acurada do mundo. A história da ciência representaria, de acordo com essa visão, uma contínua emancipação com respeito à percepção ingênua do mundo, que nossos sentidos nos fornecem.

Embora Lorenz matize que o progresso científico move-se no horizonte de um realismo hipotético (e, por isso, constantemente falível), não vejo como a sequência de 
bootstraps epistemológicos que, conforme sua caracterização, seriam próprios desse progresso possam realmente aproximar-nos da coisa-em-si. Ou, melhor dito, não vejo como Lorenz possa justificar esse mecanismo epistemológico sem postular, novamente, uma suposta adequação ao objeto que se manifesta no processo, assim como fazia Locke. Ainda que, como vimos, a adaptação ao ambiente represente uma evidência a favor do realismo e da objetividade de nossas percepções, isso não implica que nossas representações teóricas gozem do mesmo status. É plausível que elas sejam apenas modelos úteis, de acordo com uma interpretação instrumentalista. Ou talvez não seja assim, mas a raiz biológica de nosso conhecimento não nos autoriza a confiar cegamente no fato de que nossas teorias descrevam a "realidade absoluta", como ela é, independentemente de nós. A evolução pode ter moldado nossas estruturas cognitivas, as bases do conhecimento humano, mas não o conteúdo mesmo desse conhecimento. ${ }^{\mathbf{1 2}}$ A justificação epistemológica da confiabilidade de nossas percepções, conferida pela teoria da seleção natural, não se transfere necessariamente a nosso conhecimento conceitual. Assim sendo, pretender alcançar a objetividade transcendendo nossos limites biológicos pode ser um ideal lícito, mas não é suportado pela perspectiva darwinista; trata-se de pura especulação metafísica. ${ }^{\mathbf{1 3}}$

A questão central é, mais uma vez, que seria mais coerente com o darwinismo que Lorenz não distinguisse entre o homem e o animal, ao menos no que ele diz a respeito das representações "imediatas" da realidade, fornecidas pelos a priori do conhecimento fenomênico. Organismos adaptados a um determinado nicho ecológico têm, aproximadamente, iguais possibilidades de sobrevivência, e isso significa - de acordo com os pressupostos naturalistas - que seus "órgãos a priori" representam razoavelmente bem o ambiente. Não vale a intuição contrária, de que os animais confundem mais facilmente um estímulo objetivo e uma aparência (como no caso do comportamento reflexo, do imprinting etc.); também o ser humano, no nível de sua experiência fenomênica, está constantemente sujeito a erros desse tipo (ilusões óticas, erros de paralaxe etc.). Nem o animal nem o ser humano têm sempre a possibilidade de corri-

12 De fato, é costume distinguir dois projetos diferentes e autônomos sob o mesmo rótulo de epistemologia evolutiva: o primeiro, dedicado à explicação da evolução dos mecanismos epistemológicos (conhecido, em inglês, como EEM) não comporta nenhum posicionamento com respeito ao segundo, a epistemologia evolucionista das teorias (EET). Ver, por exemplo, várias contribuições em Martinez \& Olivé, 1998, e, em particular, Bradie, 1998 [1986], que propôs originariamente a distinção entre os dois projetos.

13 Novamente, Lorenz mostra sua ambivalência e sua capacidade crítica advertindo que "o fato de que seja possível fazer abstração das estruturas especificamente humanas, tal como se pratica em grande medida em todas as considerações matemáticas das ciências teóricas naturais, não deve levar-nos a crer que as concepções menos antropomórficas possuam um grau superior de realidade e que se aproximem mais do 'em si' das coisas que as concepções caracterizadas por sua ingênua evidência. Uma reprodução primitiva do mundo possui uma relação com o absolutamente existente do mesmo modo que uma superior" (Lorenz, 1984, p. 113; grifo meu). 
gir aquilo que aparenta ser uma distorção da imagem "real" do mundo. Isto é, nem o animal nem o ser humano podem confiar totalmente em seus próprios a priori, embora, do ponto de vista biológico, estes sejam tudo o que possuem para experimentar a "realidade". Eles, de acordo com os pressupostos explicitados no item 2, formam parte da realidade.

Minha sugestão é que um conceito epistemologicamente interessante de objetividade, além daquele proposto pela teoria física, poderia ser fornecido pela comparação das percepções das várias espécies em um determinado ambiente. Nesse sentido, a proposta lorenziana não deveria ser interpretada como uma superação da localização epistemológica atual do ser humano, mas como uma integração das perspectivas fenomênicas das várias espécies. A ideia de chamar esse projeto de epistemologia ecológica depende do fato de que, embora também essa perspectiva esteja baseada em uma naturalização de raiz evolucionista darwiniana, a ênfase da pesquisa está na constituição de um ambiente cognoscitivo, constituído pela confluência de diversas perspectivas particulares, e não em uma progressão de formas de conhecimento.

Ainda que os indícios sejam mais escondidos em seus escritos, considero que Lorenz apoie esse projeto, paralelamente ao da epistemologia evolutiva. Em particular, em suas numerosas referências a von Uexküll (1921), ele reconhece a necessidade de encontrar a objetividade na própria constituição fenomênica de cada espécie (que von Uexküll chama de Umwelt).

Jakob von Uexküll disse uma vez que todos os objetos que se encontram no ambiente vital de um animal são objetos de ação. Em particular, pode-se dizer que o são todas as coisas do ambiente tornadas íntimas através da exploração e depois colocadas ad acta pelos animais dotados de curiosidade. Sem dúvida, são "objetivadas" em um sentido distinto e superior, desde que o animal adquira e acumule seu saber sobre como elas podem ser utilizadas, independentemente da pressão ocasional de situações pulsionais mutáveis (Lorenz, 1974, p. 251).

Nessa interessante passagem, Lorenz reconhece que a realidade ambiental não é "morta" como o númeno kantiano, mas um conjunto de elementos carregados de significados, ativados pela interação do animal com eles. Essa atividade de, poderíamos dizer, significação do real, que corresponde a uma objetivação dos elementos relevantes para o indivíduo e deixa de lado as "aparências" que constituem o horizonte do conhecimento, funciona por meio de mecanismos gestálticos (cf. Lorenz, 1993, cap. 3 e 7). Reconhecer o papel ativo e significante do organismo não implica, em minha opinião, uma recaída idealista; ao contrário, reforça a interpretação realista com novos elementos. Por exemplo, em certas ocasiões, Lorenz parece acreditar que até os valores pertencem ao mundo natural, que podem ser tornados vivos e reais graças à atividade cognoscitiva dos animais e do ser humano. 
Nossas percepções subjetivas dos valores manifestam-se como o lado vivencial de uma reação específica e, sem dúvida alguma, inata que, independentemente de toda experiência prévia, responde, com a constância e o caráter previsível do reflexo não condicionado, a determinadas situações do entorno, que se podem abstrair com surpreendente facilidade e revelam um parentesco imediato com os autênticos esquemas inatos. Tal reação baseia-se em ditos esquemas e os tem como premissas; é provável que ela até seja idêntica a eles (cf. Lorenz, 1993, p. 33).

Ou seja, é conjecturável que certa correspondência entre o objeto de conhecimento e o esquema a priori seja dada também no plano valorativo. Não sei se podemos chegar a essas conclusões sem ter que postular de novo, como Locke, uma "conformidade" metafísica entre os conceitos e as coisas. Considero, não obstante, que uma análise comparativa entre o homem e o animal deveria ser conduzida usando esses pressupostos "igualitários". Essa análise partiria, então, da hipótese de que a significação e, de acordo com ela, a objetivação da realidade não precisam de recursos conceituais muito especializados, mas de esquemas a priori disponíveis em qualquer nível de complexidade evolutiva.

Mas como deveríamos desenvolver, na prática, essa epistemologia ecológica? Lorenz, infelizmente, não dá sugestões explícitas nesse sentido, além de algumas comparações práticas entre os animais. Em (1984 [1941]), por exemplo, ele tenta definir o espaço a partir de três representações distintas: as do rato de esgoto, do musaranho e do ganso comum. O primeiro explora o ambiente mediante movimentos retos; o segundo apresenta um comportamento caracterizado por movimentos irregulares; e, finalmente, o último é condicionado pela presença de fontes de luz. Conhecendo a fisiologia das três espécies, Lorenz considera que o comportamento do ganso comum, que não precisa de muita luminosidade em seus deslocamentos, é devido a fatores quase "religiosos":

[o ganso] está impedido por esse tipo de inibição peculiar que encadeia também os homens primitivos aos costumes. O sentido biológico desse aferro rígido à tradição é facilmente compreensível: para um organismo que não dispõe de uma visão de conjunto temporal, espacial e causal, o mais recomendável é que se ajuste rigidamente a um comportamento que já foi comprovado na prática como bemsucedido e carente de perigo. O chamado pensamento mágico, que não é de maneira alguma exclusivo dos homens primitivos, encontra-se estreitamente relacionado com esse fenômeno. Em certos comportamentos supersticiosos pensem apenas no conhecido bater na madeira - aprecia-se claramente a motivação. "Não se pode saber o que aconteceria se deixássemos de fazê-lo" (Lorenz, 1984, [1941], p. 108-9). 
Eis aqui uma amostra de análise ecológica, no sentido sugerido anteriormente. O ganso não é antropomorfizado, isto é, seu comportamento não é considerado como um mero antecedente evolutivo do comportamento humano, nem a particularidade do homem é reduzida a sua raiz comum com o animal. Cada padrão de comportamento é compreendido na sua peculiaridade dentro de um esquema que privilegia, como categorias, as modalidades de interação ambiental. Nessa direção, por exemplo, o psicólogo (de inspiração gestaltista) James Jerome Gibson (cf. 1979) tem desenvolvido a ideia de um ambiente dinâmico, que deve sua objetividade justamente às interpretações dos estímulos dadas pelos animais que nele vivem. Gibson elabora um modelo de conhecimento perceptivo/fenomênico que chama também de "ecológico" e sustenta uma versão fraca de realismo direto (ou seja, não mediado pela conceitualização), que, imagino, poderia ser aceita por Lorenz. A percepção é dinâmica e é determinada por affordances, estímulos pragmáticos que derivam de uma interação entre os sentidos e o ambiente. A possibilidade de interagir com um objeto depende de um reconhecimento das "atitudes fenomênicas" dele, que são definidas a partir da faculdade do organismo de perceber qualidades espaciais como a luminosidade, a cor, a distância ou a forma. $\mathrm{Na}$ linguagem adotada aqui, esses seriam os a priori naturalizados, responsáveis por determinados acessos à realidade e, até certo ponto, pela constituição dessa realidade.

\section{Conclusões}

Pouco tempo depois da publicação de Lorenz (1974), apareceu em Philosophical Review um breve artigo que ocasionou muita discussão nos ambientes da filosofia da mente, "Como é se sentir um morcego?" de Thomas Nagel (1974). Nesse trabalho, o autor discutia a impossibilidade de estudar o componente fenomênico do conhecimento em outros indivíduos ou espécies. Trata-se de um obstáculo intrínseco ao nosso acesso epistemológico, irremediavelmente subjetivo, que, uma vez aceito, implicaria o fracasso das teorias materialistas da mente. Mais drasticamente, para Nagel (cf. 2012), a incapacidade de dar conta de alteridades epistemológicas implicaria a inadequação de boa parte da ciência atual e, em particular, da teoria da seleção natural.

Não participo do pessimismo de Nagel. $\mathrm{O}$ acesso epistêmico limitado, com respeito ao mundo fenomênico de outro organismo, não é uma boa razão para renunciar à conjectura de novos modelos naturalistas sobre a alteridade animal. O problema, ao fim e ao cabo, nunca é o de "entrar" na cabeça de um morcego ou de qualquer outro animal. Queixar-se de que não podemos saber como é sentir-se um animal é absurdo, pois devemos desenvolver nossas teorias com os meios a nossa disposição. Com relação à análise do espaço que expus brevemente acima, Lorenz diz que 
muitos animais não captam da mesma maneira que nós a estruturação "espacial" do seu mundo. Mas nós podemos ter uma ideia aproximada de como é o "espacial" na imagem do mundo dessas criaturas precisamente porque, junto com nossa própria concepção espacial, possuímos também a mesma faculdade para o domínio das tarefas espaciais (Lorenz, 1984, [19411], p. 107).

Ou seja, parafraseando um pouco poeticamente, nós também possuímos uma animalidade transcendental, a faculdade de compreender os modos de compreensão dos animais, assim como compreendemos os dos nossos semelhantes humanos. Não é obviamente uma compreensão perfeita, como tampouco é perfeita a compreensão dos outros humanos, mas pode ser suficiente para empreender um projeto epistemológico como o que Lorenz, para além de seus excessos evolucionistas, estava sugerindo.@

Lorenzo Baravalle

Centro de Ciências Naturais e Humanas, Universidade Federal do ABC, Brasil. lorenzo_baravalle@yahoo.it

Transcendental animality: the problem of naturalizing the a priori in Konrad Lorenz

\begin{abstract}
One of the main features of Konrad Lorenz's epistemological foundation of ethology is the attempt of synthesis between Darwinian theory and Kantian gnosiology. Starting from this premise I will outline, first of all, a brief history of transcendentalist tradition, focusing attention on some elements that its critics have regarded as untenable. Secondly, I will analyze Lorenz's attempt to implant the transcendental structure in his ethological researches as being a consequence of the naturalization of the concept of "a priori". Thirdly, I will see how the attribution of a priori proper to single species opens the possibility of interpreting the epistemology of Lorenz in two apparently conflicting ways. Finally, I will prefer one of these interpretations and I will show that it enables us to understand the distinct modalities of animal and human knowledge.
\end{abstract}

KEYwords • Animals. Humans. A priori. Evolutionary epistemology. Naturalism. Transcendentalism. Darwinism. 
Animalidade transgendental: o Problema da naturalização...

\section{REFERÊNGIAS BIBLIOGRÁFIGAS}

Allison, E. Kant's transcendental idealism. New Heaven: Yale University Press, 1983.

Ayala, F. J. \& Dobzhansky, T. (Ed.). Studies in the philosophy of biology. New York: Macmillan, 1974.

Bateson, G. Mente e natura. Milano: Adelphi, 1979.

Berkeley, G. Principles of human knowledge. New York: Macmillan, 1965 [1710].

Bird, G. Kant's theory of knowledge. New York: Routledge \& Kegan Paul, 1962.

Boghossian, P. \& Peacocke, C. (Ed.). New essays on the a priori. London: Clarendon Press, 2000.

Bradie, M. Una evaluación de la epistemología evolucionista. In: Martínez, F. \& Olivé, L. (Ed.). Epistemología evolucionista. Barcelona: Paidós, 1998 [1986]. p. 243-84.

Bruner, J, S. et al. (Ed.). Contemporary approaches to cognition. Cambridge: Harvard University Press, 1957 .

Brunswik, E. Scope and aspects of the cognitive problems. In: Bruner, J. S. et al. (Ed.). Contemporary approaches to cognition. Cambridge: Harvard University Press, 1957. p. 5-31.

Gampbell, D. T. Evolutionary epistemology. In: Schilpp, P. (Ed.) The philosophy of Karl Popper. La Salle: Open Court, 1974a. p. 413-63.

. Unjustified variation and selective retention in scientific discovery. In: Ayala, F. J. \& Dobzhansky,

T. (Ed.). Studies in the philosophy of biology. New York: Macmillan, 1974b. p. 139-61.

CAponi, G. Tipología y filogenía de lo humano. Ludus Vitalis, 20, 37, p. 175-91, 2012.

CARnap, R. The logical structure of the world. Berkeley: University of California Press, 1967 [1928].

Empiricism, semantics and ontology. Revue Internationale de Philosophie, 4, p. 20-4,0, 1950.

Cassirer, E. Kant, vida y doctrina. Ciudad de México: Fondo de Cultura Económica, 194.8 [1918].

Coffa, J. A. The semantic tradition from Kant to Carnap. To the Vienna station. Cambridge: Cambridge University Press, 1991.

Cranagh, A. Prólogo. In: Lorenz, K. La ciencia natural del hombre. Barcelona: Tusquets, 1993. p. 13-20.

Gibson, J. J. The ecological approach to visual perception. Boston: Houghton Mifflin, 1979.

Giere, R. N. Philosophy of science naturalized. Philosophy of Science, 52, p. 331-56, 1985 .

Kant, I. Critica della ragion pura. Torino: UTET, 1986 [1781/1787].

Locke, J. An essay concerning human understanding. New York: Dover, 1959 [1690].

LoRenz, K. L'altra faccia dello specchio, Milano: Adelphi, 1974. La teoría kantiana de lo apriorístico bajo el punto de vista de la biología actual. In: Lorenz, K. \&

Wuketits, F. M. (Ed.). La evolución del pensamiento. Barcelona: Editorial Argos Vergara, 1984 [1941]. p. 89-116. . La ciencia natural del hombre. "El manuscrito de Rusia" (1944-1948). Barcelona: Tusquets, 1993.

Lorenz, K. \& Wuketits, F. M. (Ed.). La evolución del pensamiento. Barcelona: Editorial Argos Vergara, 1984 .

Lumsden, C. \& Wilson, E. O. Genes, mind, and culture. Cambridge: Harvard University Press, 1981.

Maddy, P. Naturalism and a priori. In: Boghossian, P. \& Peacogke, C. (Ed.). New essays on the a priori. London: Clarendon Press, 2000. p. 92-116.

Marcugci, S. Guida alla lettura della Critica della ragion pura di Kant. Bari: Editori Laterza, 1997.

Margalef, R. Presentación. In: Lorenz, K. La ciência natural del hombre. Barcelona: Tusquets, 1993. p. $7^{-11 .}$

Martínez, F. \& Olivé, L. (Ed.). Epistemología evolucionista. Barcelona: Paidós, 1998.

MaYr, E. L'evoluzione delle specie animali. Torino: Einaudi, 1970.

Munz, P. Philosophical Darwinism. London: Routledge, 1993. 
NAGEL, T. What is it like to be a bat? Philosophical Review, 83, 4, p. 435-50, 1974 .

Mind and cosmos: why the materialist neo-Darwinian conception of nature is almost certainly false.

Oxford: Oxford University Press, 2012.

Popper, K. R. Conjectures and refutations. London: Routledge \& Kegan Paul, 1962.

Objective knowledge: an evolutionary approach. Oxford: Oxford University Press, 1972.

Quine, W. V. O. From a logical point of view. New York: Harper \& Row, 1963.

. Ontological relativity and other essays. New York: Columbia University Press, 1969.

Ruse, M. Taking Darwin seriously. Oxford: Blackwell, 1986.

Schilpp, P. (Ed.). The philosophy of Karl Popper. La Salle: Open Court, 1974.

Thagard, P. En contra de la epistemología evolucionista. In: Martínez, F. \& Olivé, L. (Ed.). Epistemología evolucionista. Barcelona: Paidós, 1998 [1980]. p. 285-95.

UEXKüLL, J. von. Umwelt und Innenleben der Tiere. Berlin, 1921.

VecGhi, D. \& Baravalle, L. A critical evaluation of Popper's evolutionary philosophy. No prelo. 